\title{
Impact and Post Impact Behavior of Hybrid Composites
}

\author{
Aidel Kadum Jassim Al-shamary ${ }^{1}$, Akar Dogan ${ }^{2}$, Okan Ozdemir ${ }^{3}$, Ramazan Karakuzu ${ }^{4}$ \\ Department of Soil Science and Water Resources, College of Agriculture, University of Diyala \\ 2, 3, 4 Department of Mechanical Engineering, Dokuz Eylul University, Izmir, Turkey. \\ adel_kadum500@yahoo.com ${ }^{1}$
}

\begin{abstract}
In this study, the effect of low velocity impact response of Kevlar/carbon hybrid composite has been investigated. Then the impacted specimens were subjected to compression and buckling tests at room temperature experimentally. The height, width and thickness of the specimens are 150, 100 and $2.1 \mathrm{~mm}$, respectively. Impact tests have been performed under different impact energy levels by using low velocity impact testing machine. Compression and buckling tests were conducted by Shimadzu testing machine. According to obtained results, the damage increases by increasing the impact energy level in the subjected specimens to impact test. Compression strength value is higher about 3 times than buckling strength value.
\end{abstract}

Keywords: Hybrid Composites, Kevlar/Carbon, Woven, compression after impact, buckling after impact, Low Velocity Impact.

Paper History: (Received: 24/4/2017; Accepted: 2/7/2017)

Nomenclature

MWCNTs Multi-walled carbon

GO
PPy
WKF
PES
VARTM

CFRP

PP

HVI

MGS L160

MGS H160

LVI

Shimadzu AG

with50 kN

$\mathrm{Ei}$

$\mathrm{Ea}$

DAS

MAg
Multi-walled carbon
nanotubes

Grapheme oxide Polypyrrole

Woven Kevlar fibers Polyester resin

Vacuum-assisted resin transfer molding

Carbon fiber reinforced polymer Polypropylene

High velocity impact Resin Hardener

Low velocity impact

Test machine

Impact energy

Absorbed energy

Data acquisition system

Maleic anhydride grafted

\section{Introduction}

In the last few years, Kevlar and Carbon have been used as fiber-reinforced in structural engineering of aerospace and automobile industries due to their superior performances such as high strength, low weight by comparing to the metallic materials, and high stiffness etc. The objective of this study is to show the effect of low velocity impact on fabric of hybrid composite materials. The impact response of composite materials is mainly affected by fiber materials, matrix and their thickness.

Woo and Kim [1] studied carbon/Kevlar hybrid composite with a $2 * 2$ twill weave pattern, by using compressive test. The result showed that the failure of carbon/Kevlar hybrid woven composite materials occurred as breakage at Carbon and Kevlar fibers. Composite material used in liners was manufactured by Lu et al [2] using PTFE/Kevlar fabric woven. Elastic performances of liners with main directions during wear process have investigated and the results show that contact pressures affected by wear depth in spherical plain bearings. Furthermore, Taraghi et al [3] carried out a study consisting of Kevlar and Carbon to produce laminated composites; studied low velocity impact response under two conditions of temperature at $27{ }^{\circ} \mathrm{C}$ and $-40{ }^{\circ} \mathrm{C}$. The absorbed energy increased about $35 \%, 34 \%$ at $27{ }^{\circ} \mathrm{C}$ and at $-40{ }^{\circ} \mathrm{C}$, respectively by adding MWCNTs.

High strain rate compression loading carried out by Kapoor et al. [4]. Vacuum assisted compression molding technique was used to produce composite laminates which consist of 8 and 24 layers of kevlar fiber polypropylene resin. Peak stress, toughness and strain at peak stress increased as explained in the result. Gilart and co-authors [5] developed composite materials by using carbon-based to obtain higher thermal conductivity and the new materials show an increased about $576 \%$ in thermal conductivity than pure material.

Kostopoulos et al [6] studied the effective of adding multi-wall carbon nanotubes on the 
impact response, Carbon fibers as reinforced were used to manufacture laminates. Prepared samples were subjected to low velocity impact (LVI) and compressive test, the results showed that samples were developed by addition $0.5 \%$ per weight of (MWCNTs) to epoxy resin comparing with pure resin.

Vacuum-assisted resin transfer molding (VARTM) was used by Hazarika et al [7] to prepare samples composite of carbon nanotubes and woven Kevlar fiber. The tensile strength and absorbed energy increased for composite due to the interactions between GO, WKF, PPy, and PES.

Related researches about low velocity impact tests and carbon fibers could be also found in Farooq and Myler [8] and Li et al. [9]. Comparison between the flat nose and round nose of impactor was studied by Farooq and Myler using low velocity impact test; carbon fibers as reinforced in laminated were used to manufacture three types of composite with different layers 8, 16 and 24 layers. The results showed that deflections of thin laminates were produced by using flat nose impactor more than round nose impactor. The infrared thermography and ultrasonic infrared thermography were applied by $\mathrm{Li}$ and coauthors on the specimens of composite after using low velocity impact test. The damage in Carbon fiber reinforced polymer (CFRP) was found by using two detection methods.

Compression molding technique was used by Bandaru et al [10] to manufacture two homogeneous and three hybrids composite laminates of Kevlar and basalt fibers with polypropylene (PP) resin. The properties of composite material like elastic modulus, strength were improved due to the hybridization composite of Kevlar and basalt fibers. The quasi static transverse compression behavior of Kevlar KM2 has studied performance of polymer fibers by using high velocity impact (HVI). Compressed width growth as results was found at higher load levels [11].

Bandaru et a [12] studied the post-impact response of the composites laminates. Composite laminates with two-dimensional and three-dimensional were manufactured by using Kevlar fabrics and polypropylene resin, specimens of composite were subjected to low velocity impact (LVI). The results show that the energy absorption of 3D is higher than energy absorption in the samples the $2 \mathrm{D}$. The interfacial property improved adding $10 \%$ MAg-PP to the PP matrix.

Two modules of low thermal conductivity and high thermal conductivity were manufactured by using carbon foams [13]. Specimens of composite materials were subjected to the pulsed power; Damping was more explained in stand-alone pulse power cycles at comparing with pulsed power spikes modes as a result. In addition, Aleksandrov and Prosuntsov [14] investigated in effect the carbon on thermophysical characteristics of composite Materials experimentally. The thermal conductivity of a polymer was studied by using carbon nanotubes; the obtained result shows that carbon nanotubes cannot increase the thermal conductivity. Composites of Carbon, Glass and Kevlar with epoxy were also studied by Julias et al [15]. Hand lay-up technique was used to manufacture composites lamina, tensile test conducted on composites to evaluate performance fibers of Carbon, Glass and Kevlar. Result shows that direction fiber affected on tensile test.

\section{Experimental Investigation}

2.1. Materials and Manufacturing of Specimens

Woven kevlar and carbon fibers were used as rein forcing material to manufacture laminated composite plates. Laminating Resin MGS L160 and a Hardener MGS H160 have been chosen as a matrix material with ratio of $4: 1$ of the resin and hardener. Prepared specimens of laminated composite plates carried out by using Vacuum assisted resin infusion molding (VARIM) technique at $80{ }^{\circ} \mathrm{C}$ for 8 hours as shown in Figure 1, then the temperature decreased progressively to room's temperature. Eight laminas were located in manufacturing process; a wet cutting machine was used to produce specimens. Figure 2 shows prepared specimens of composite with dimensions of height, width and thickness as 150, 100 and 2.1 $\mathrm{mm}$, respectively.

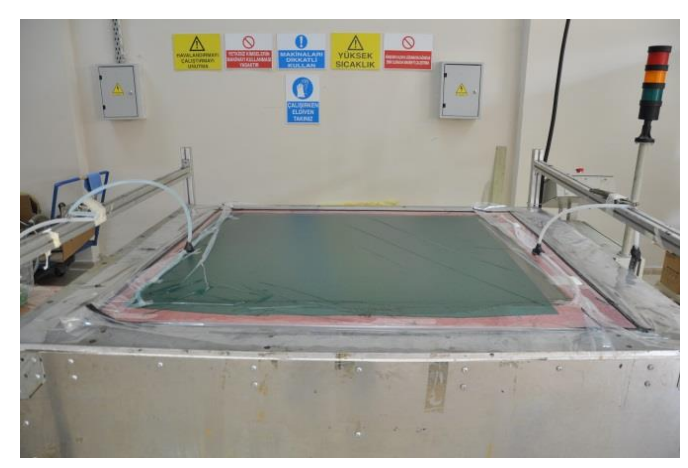

Figure 1: Vacuum Assisted Resin Infusion Molding Process 


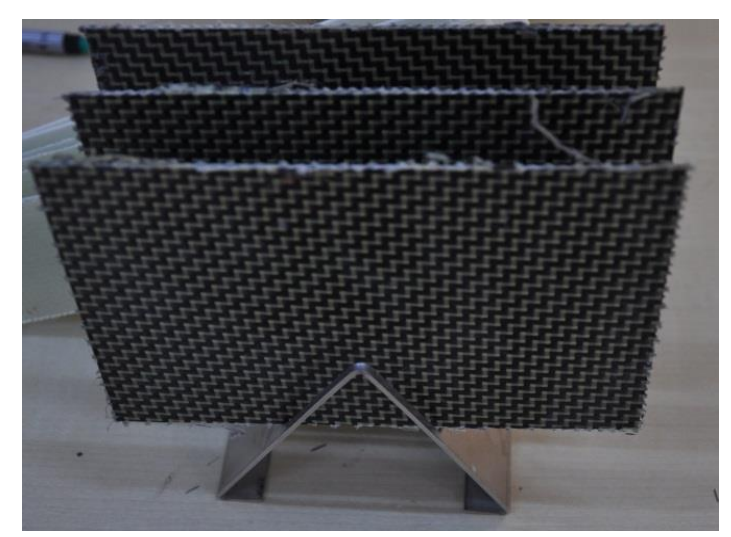

Figure 2: Prepared Specimens of Hybrid Composite

\subsection{Impact and Post-impact Testings}

Prepared specimens of laminated composite plates were subjected to low velocity impact (LVI) by using the Fractovis Plus impact testing machine as shown in Figure 3. The diameter of impactor nose was $12.7 \mathrm{~mm}$ hemispherical which was connected with force transducer which has maximum loading up to $22.4 \mathrm{KN}$, as well as the velocity and maximum energy for impact testing machine is $24 \mathrm{~m} / \mathrm{s}$ and $1800 \mathrm{~J}$, respectively. The total impact mass is $5.02 \mathrm{~kg}$ containing force transducer, impactor nose and crosshead.

Different impact energy values $(5,7.5,10,12.5$ and 15) $\mathrm{J}$ were chosen, in the experimental investigation and every test was repeated eight times for each energy level applied. The prepared specimens were based on inner diameter with $76.2 \mathrm{~mm}$ of the clamping apparatus before the impact test. The impact points was located in the center of the samples because the prepared specimens were mounted on the fixture at base of the impact machine as shown in the Figure 3-b, and during the impact tests all the data were obtained by using the advanced data acquisition system (DAS) which can give 16000 data for each test Figure 3-c. Time, force, velocity, displacement and absorbed energy were determined as results from the software of data acquisition system which based on the Newton's second law and kinematic equations.

Subsequently, the impacted specimens have been divided to two groups. The first one was subjected to buckling tests however the second group was subjected to compression test.
The dimensions of specimens were Prepared according to ASTM D 7137 with 150 mm, 100 $\mathrm{mm}$ height and width respectively, specimens of laminated composite plates were subjected to compression and buckling tests after impact test in order to study effect impact loading on the compression and buckling strength of the samples experimentally. The compression and buckling tests have been carried out at room temperature by using the Shimadzu AG with50 $\mathrm{kN}$ test machine as seen in Figure 4-a. In the buckling test, apparatus was used with two clamped ledges and two free ledges as the boundary conditions as observed in Figure 4-b. However, there aren't free ledges in the apparatus of the compression test as shown in Figure 4-c. The material strength depends on the strain value. In other word, material strength raises by increasing strain value. The results have been obtained as a text file on the data card from the test machine. Then, curves of stress-strain are obtained for each sample. The buckling and compression after impact stresses are calculated by,

$$
\sigma=\frac{F}{b * t}
$$

- Where $\boldsymbol{\sigma}, \mathrm{F}, \mathrm{b}$ and t represent stress, force, width and thickness of sample, respectively

- In this study, buckling force is not obtained analytically. Above formula is used for calculation of critical buckling stress. Where, $\mathrm{F}$ is critical buckling force obtained experimentally, $\mathrm{b}$ and $\mathrm{t}$ are width and thickness of specimen respectively. $b^{*} \mathrm{t}$ represents cross section of specimen. 

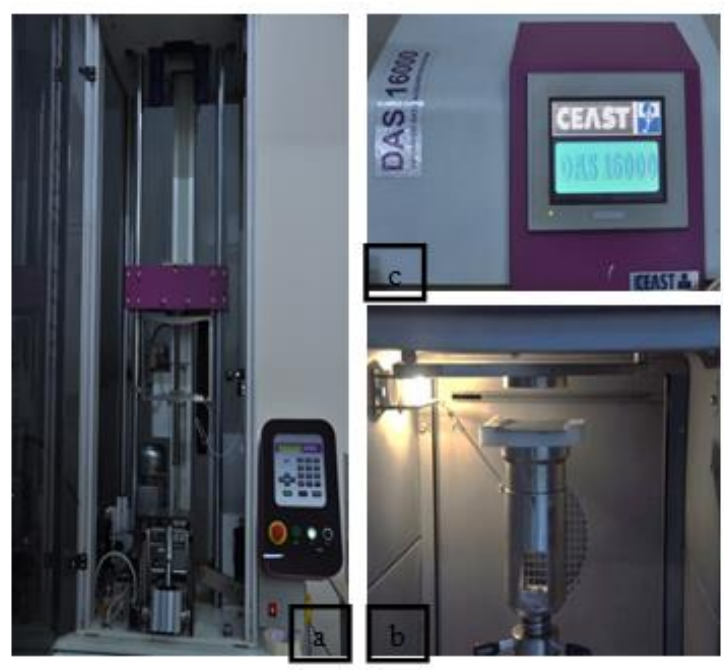

Figure 3: Impact testing machine (a) turret (b) chamber of test (c) advanced data acquisition system

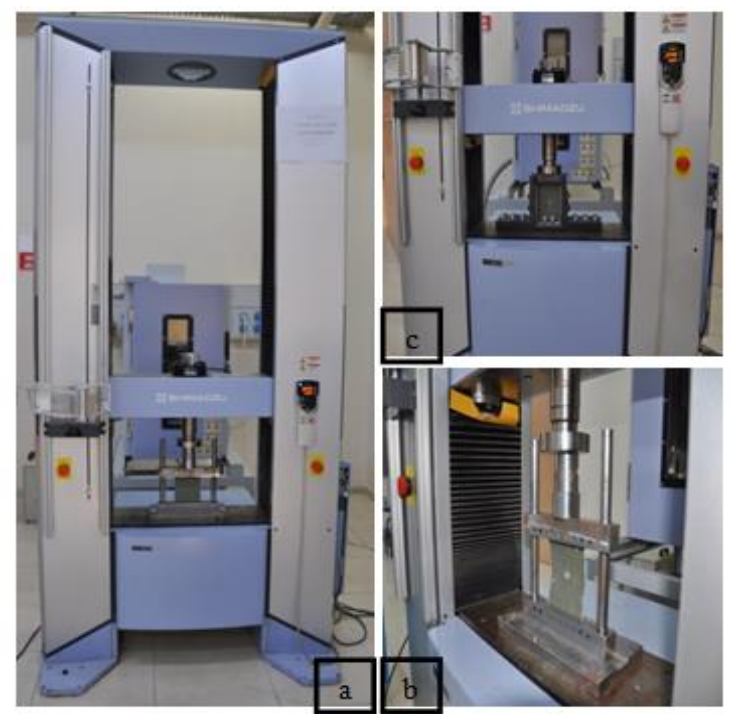

Figure 4: (a) The Shimadzu test machine (b) apparatus of buckling test (c) apparatus of compression test

\section{Results and Discussion}

The woven Kevlar/carbon composite was subjected to single impact loading at room temperature. The curves of contact force with deflection represent damage processes which consist of three modes as can be seen in the Figure 5. Firstly rebounding case occurs at return of the impactor after impact the top surface of specimen; secondly penetration case happens when the impactor impact the sample without rebound which is affected by fiber and matrix type, thirdly upward motion of the impactor after impact and happening failure in the sample this damage process is called perforation case which occurs after increasing the impact energy levels. On the other hand the rebounding threshold becomes penetration and perforation threshold, respectively.
Contact force versus deflection curves are mountain-like shaped for specimens of woven Kevlar/carbon composite laminated, all the specimens were subjected to impact test by using different impact energy value $5 \mathrm{~J}, 7.5 \mathrm{~J}$, $10 \mathrm{~J}, 12.5 \mathrm{~J}$ and $15 \mathrm{~J}$. The absorbed energy and deflection increase by increasing the impact energy as can be seen in the Figure 6, the absorbed energy can be determine from the closed area of the contact force-deflection curve during the impact test. The closed curve consist of impact bending stiffness and slopes of rebounding threshold which indicate the return of impactor after impact the top surface of specimen, It is meaning that the damage occurs as a delamination and matrix cracks by using $5 \mathrm{~J}, 7.5 \mathrm{~J}$ and $10 \mathrm{~J}$, however the penetration case happened at $12.5 \mathrm{~J}$ when the contact force value becomes zero in the end of the descending section. The perforation case is occurred by increasing the applied impact energy to 15J. As can be seen in the Figure 6the impact bending stiffness of curve decreases because fully perforation of the sample. The damage also has been increased as delamination, matrix cracks and fiber breakage in the specimens of woven Kevlar/carbon composite laminated.

Figure 7 explains energy and time response for samples of hybrid composite laminated which were subjected to different impact energy (Ei) from $5 \mathrm{~J}$ to $15 \mathrm{~J}$. The absorbed energy $(\mathrm{Ea})$ rises with increasing the applied impact energy despite of dissipate energy which occurs because the friction between the striker and specimen. Also it is clear that the complete perforation case is occurred after using $15 \mathrm{~J}$.

Three of specimens were tested in the buckling test using apparatus with two clamped ledges, while compression test carried out on five specimens using apparatus with four clamped ledges after impact loading. In the tests, all specimens were loaded uniaxially until the failure was occurred, the results showed that compression after impact strength is higher about 3 times than buckling after impact strength of the tested samples, because buckling test apparatus has two free ledges as the boundary conditions so the fibers of Kevlar and Carbon have elasticity as shown in the Figures $8 \& 9$.

The progressing of damage represents the change between incipient damage which occurs at low applied load values and complete failure in the sample of composite which is occurred at increasing applied load values. As can be seen from the Figure 10 impacted face at 5, 10 and $15 \mathrm{~J}$, the damage like delamination in specimens are subjected to compression 
after impact test is much more than the damage in specimens subjected to buckling after impact test because researcher used antibuckling blocks in order to prevent buckling in the samples under compressive test while the apparatus in the buckling test has two free edges. The damage effects by the stacking sequence, material and laminate thickness, so the extension of damage occurs according to the interlacing architecture fibers of Kevlar and Carbon as shown in the Figure 10, and according to Aktas et al [16] the damage happens close to the impact point of the specimens for both compression and buckling tests.

Fracture force of fibers is occurred because the high bending stresses which occurs in the back face of samples. The damage modes occur as delamination, matrix cracking and fiber breakage in the impact test however in the compression and buckling after impact test the damage occurs as delamination, fiber splitting and matrix cracking.
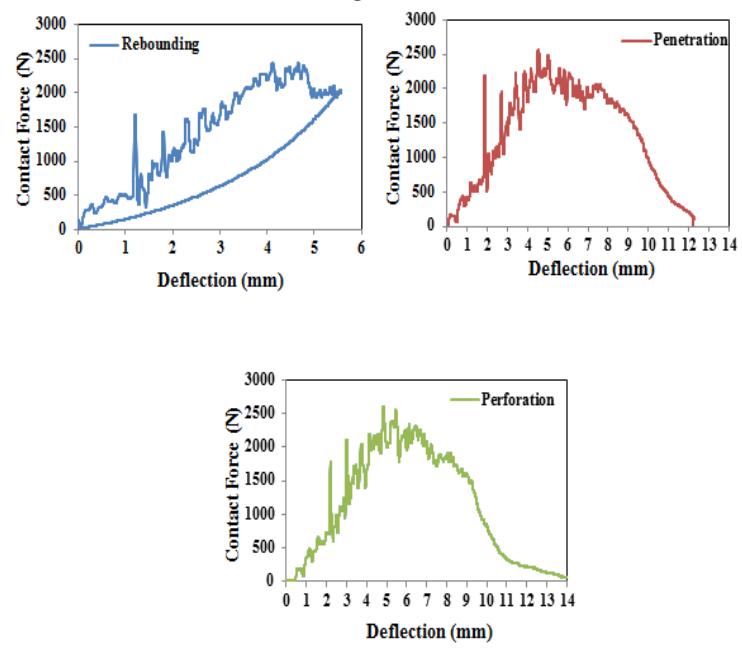

Figure 5: The typical contact force-deflection curves

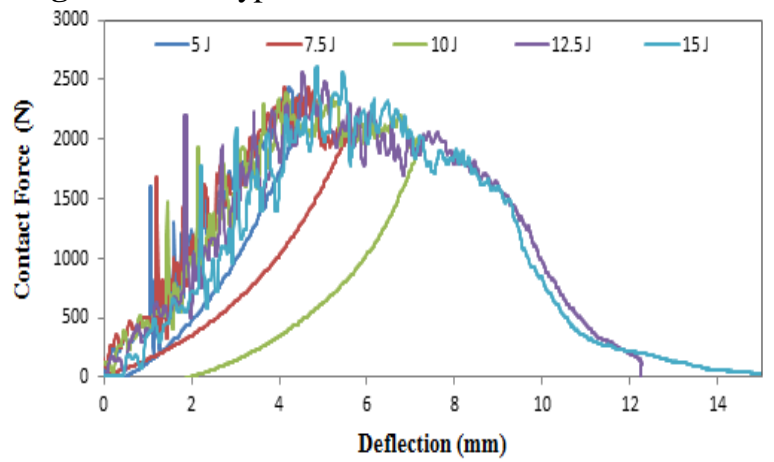

Figure 6: Contact force-deflection curves of woven composite laminated

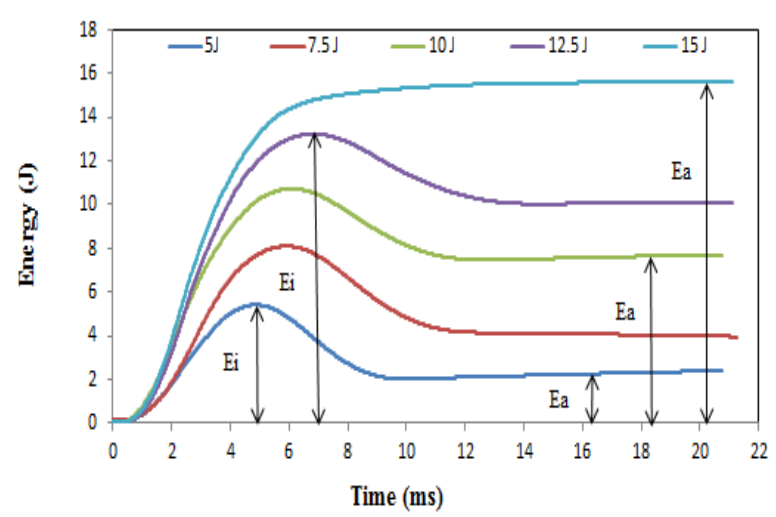

Figure 7: Energy-Time curves of woven composite laminated

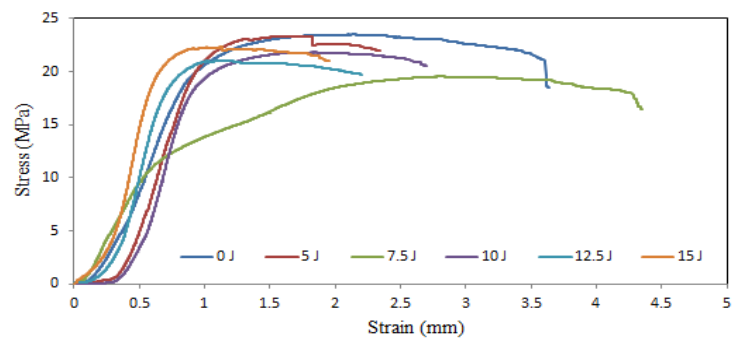

(a)

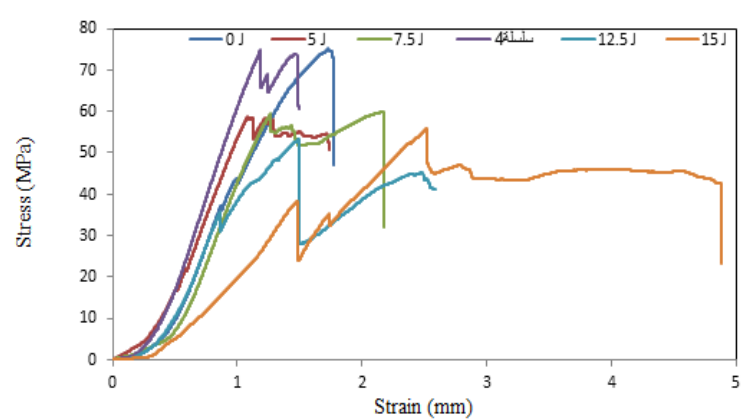

(b)

Figure 8: Stress-Strain curves of (a) buckling test and (b) compression test

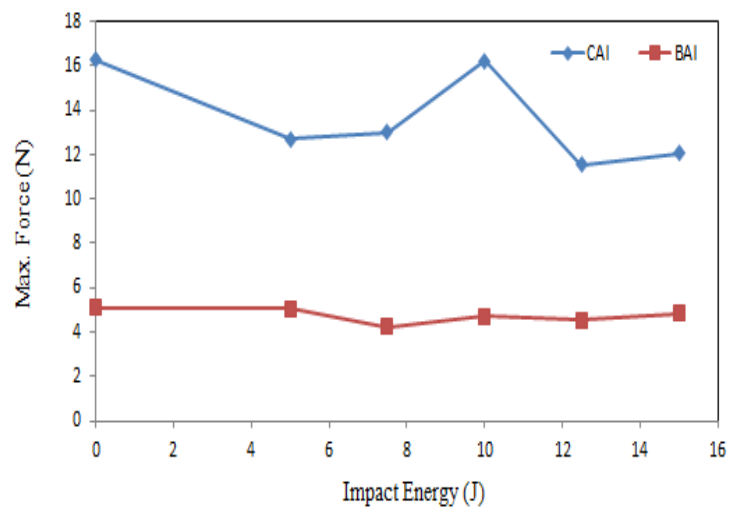

Figure 9: Max. Force-Impact Energy carves of compression and buckling after impact tests 


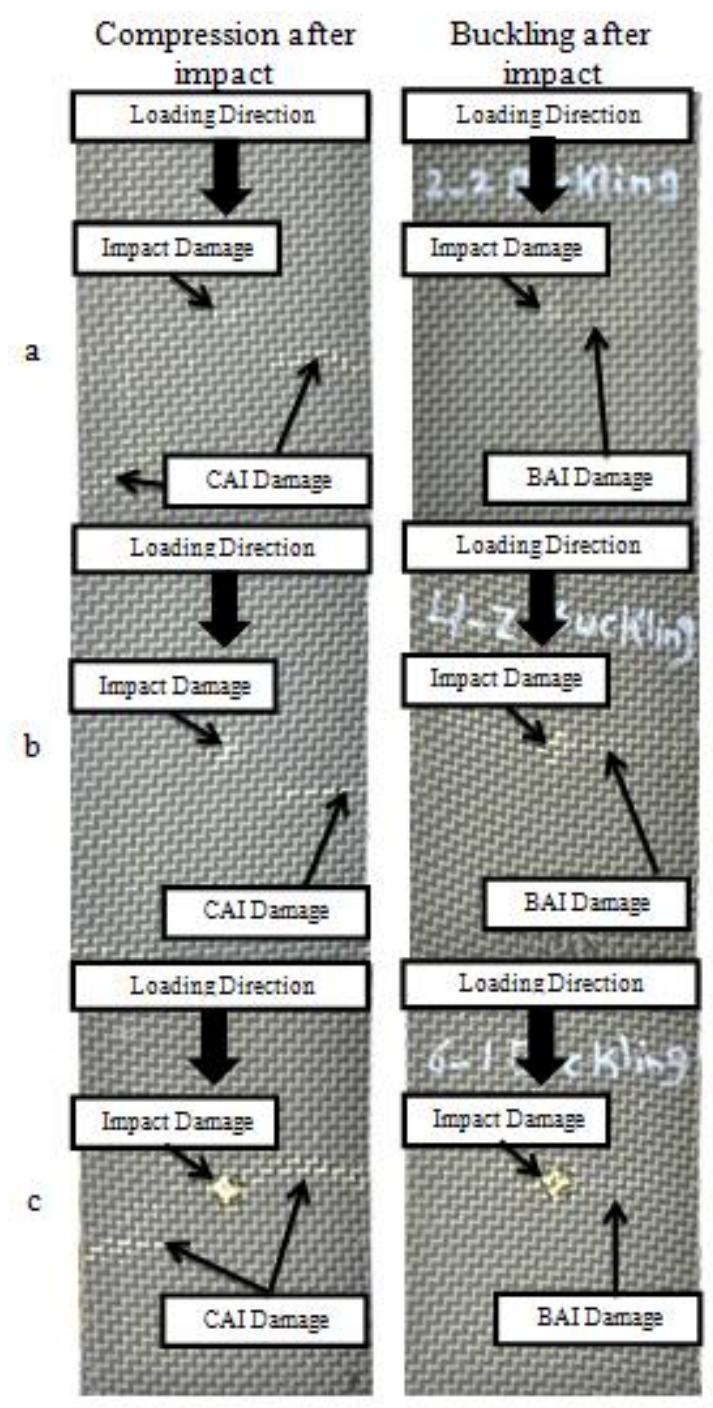

Figure 10: Damage Modes of Hybrid Composite Laminated Impacted at (a) $5 \mathrm{~J}$ (b) $10 \mathrm{~J}$ (c) $15 \mathrm{~J}$

\section{Conclusions}

In the present study, the effect of low velocity impact test on the compression and buckling tests of hybrid Kevlar/Carbon laminated composite was studied at room temperature experimentally. The Fractovis Plus impact testing machine was used in the impact test while researcher performed compression and buckling tests by using the Shimadzu AG with $50 \mathrm{kN}$ test machine. All the samples were tested in this paper have been manufactured in laboratory of composite research/Mechanical Engineering Department in University of Dokuz Eylul /Izmir/Turkey, and the important conclusions are summarized as:

- The damage area grows with higher energy intake in the specimens.

- The damage increases by increasing the impact loading, it was noted that the damage like delamination in specimens are subjected to compression test is more than the damage in specimens buckling test.
- The buckling strength after impact is lower than compression strength after impact because two free ledges in the buckling test.

- It is clear from the Figure 9 the max. Force in compression and buckling tests occurs at $0 \mathrm{~J}$ which means that the compression and buckling tests affected by impact loading test.

- The damage happens close to the impact point of the samples for both compression and buckling after impact test which means that low velocity impact effects on the fibers of Kevlar/Carbon hybrid composite laminated.

\section{References}

[1]. Woo S. C., and Kim, T. W., High strainrate failure in carbon/Kevlar hybrid woven composites via a novel SHPB-AE coupled test, Composites Part B, 97, (2016), 317-328.

[2].Lu, J., Qiu, M., and Li, Y., Wear models and mechanical analysis of PTFE/Kevlar fabric woven liners used in radial spherical plain bearings, Wear, 364-365, (2016), 57-72.

[3].Taraghi, I., Fereidoon, A., and Behrooz, F. T., Low-velocity impact response of woven Kevlar/epoxy laminated composites reinforced with multi-walled carbon nanotubes at ambient and low temperatures, Materials and Design, 53, (2013), 152-158.

[4]. Kapoor, R., Pangeni, L., Bandaru, A. K., Ahmad, S., and Bhatnagar, N., High strain rate compression response of woven Kevlar reinforced polypropylene composites, Composites Part B, 89, (2016), 374-382.

[5]. Gilart, P. M., Martı'nez, A. Y., Barriuso, M. G., and Martı'nez, C. M., Development of $\mathrm{PCM}$ /carbon-based composite materials, Solar Energy Materials \& Solar Cells, 107, (2012), 205-211.

[6]. Kostopoulos, V., Baltopoulos, A., Karapappas, P., Vavouliotis, A., and Paipetis, A., Impact and after-impact properties of carbon fibre reinforced composites enhanced with multi-wall carbon nanotubes, Composites Science and Technology, 70, (2009), 553-563. [7].Hazarik, A., Dek, B. K., Kim, D., Park, Y. B., and Park, H. W., Microwave-induced hierarchical iron-carbon nanotubes nanostructures anchored on polypyrrole/graphene oxide-grafted woven Kevlar fiber, Composites Science and Technology, 129, (2016), 137-145.

[8].Farooq, U., and Myler, P., Efficient computational modelling of carbon fibre reinforced laminated composite panels subjected to low velocity drop-weight impact, Materials and Design, 54, (2013), 43-56.

[9].Li, Y., Zhang, W., Yang, Z. W., Zhang, J. Y., and Tao, S. J., Low-velocity impact 
damage characterization of carbon fiber reinforced polymer (CFRP) using infrared thermography, Infrared Physics \& Technology, 76, (2016), 91-102.

[10].Bandaru, A. K., Patel, S., Sachan, Y., Ahmad, S., Alagirusamy, R., Bhatnagar, N., Mechanical behavior of Kevlar/basalt reinforced polypropylene composites, Composites: Part A, 90, (2016), 642-652.

[11].Sockalingam, S., Bremble, R., Jr, J. W. G., and Keefe, M., Transverse compression behavior of Kevlar KM2 single fiber, Composites: Part A, 81, (2015), 271-281.

[12].Bandaru, A. K., Chavan, V. V., Ahmad, S., Alagirusamy, R., and Bhatnagar, N., Low velocity impact response of $2 \mathrm{D}$ and $3 \mathrm{D}$ Kevlar/polypropylene composites, International Journal of Impact Engineering, 93, (2016), 136-143.

[13].Alshaer, W. G., Rady, M. A., Nada, S. A., Barrio, E. P., and Sommier, A. An experimental investigation of using carbon foam-PCM-MWCNTs composite materials for thermal management of electronic devices under pulsed power modes, Heat Mass Transfer, 53: (2016), 569-579.

[14].Aleksandrov, I. A., and Prosuntsov, P. V. Determination of the Effect of Carbon Nanosized Particles on Thermophysical Characteristics of Polymer Composite Materials, Polymer Science, Series D, 9, (4), (2016), 377-381.

[15].Arockia, J. A., Ram, K. N., avd Murali, V. Evaluation of Lamina Properties and Fractographic Studies on Glass/Epoxy, Carbon/Epoxy and Kevlar/Epoxy Composites, Applied Mechanics and Materials, 813-814, (2015), 46-50.

[16].Aktas, M., Karakuzu, R., and Arman, Y. Compression-after impact behavior of laminated composite plates subjected to low velocity impact in high temperatures, Composite Structures, 89, (2008), 77-82. 